\title{
A análise do projeto político pedagógico como instrumento de reflexão da escola como comunidade em cursos de formação de professores
}

\author{
Luiz Carlos Souza Bezerra \\ PUC - SP
}

\begin{abstract}
Resumo
Pretende-se, neste trabalho, compreender a análise do projeto político pedagógico (PPP) como instrumento de reflexão da escola como comunidade. O PPP não é entendido no sentido stricto senso de formalização do trabalho didático, mas em sentido lato senso, mais amplo, ou seja, o PPP é constituído a partir de conceitos e significados, de experiências permeadas por valores simbólicos que incidem na prática docente, na articulação da unidade escolar, na relação da escola com a sociedade, na relação do professor-aluno. Para tanto, os dados de análise consistem em relato de experiência com formação de professores de escolas públicas desenvolvida em uma cidade no interior do Estado do Ceará. Os resultados preliminares revelam que os professores apresentavam dificuldades e resistência em compreender o PPP como uma proposta de formação e transformação da unidade escolar e, que, por sua vez, possui sentidos importantes na construção da identidade da instituição.
\end{abstract}

Palavras-chave: projeto político pedagógico, escola, comunidade, formação de professores.

\begin{abstract}
This paper aims to understand the analysis of the Political Pedagogical Project (PPP) as an instrument of reflection on the school as a community. The PPP is not conceived of in the strict sense of the formalization of the didactic work, but in a broader sense. That is, the PPP is constituted by concepts and meanings, by experiences permeated by symbolic values that influence the teaching practices, the articulation of the school unity, the relation between school and society, and teacherstudent relations. The data under analysis consists of the narration of teacher education-related experiences in a city in the state of Ceará. Preliminary results show that teachers found it difficult to understand the PPP (or resisted understanding it) as a proposal of formation and transformation of the school unity that plays an important role in the construction of the identity of the institution.
\end{abstract}

Keywords: political pedagogical project, school, community, teacher education.

\section{INTRODUÇÃO}

Este trabalho discute a importância do Projeto Político Pedagógico, doravante denominado PPP, na organização da comunidade escolar e de práticas de ensino. Mais precisamente, propõe-se analisar a escola como comunidade e o papel da construção e efetivação do PPP na organização e funcionamento dessa comunidade. Portanto, acrescenta-se 
ainda que não concebemos o PPP apenas como um documento burocrático e sim, compreendemos como uma instância de constituição de identidade e de práticas identitárias.

O PPP e sua organização têm sido bastante discutidos na área da educação. Conforme Veiga (2013, p. 11), o PPP tem-se constituído como "objeto de estudos para professores, pesquisadores e instituições educacionais em nível nacional, estadual e municipal, em busca da melhoria da qualidade do ensino". Porém, nota-se, por um lado, que as discussões ainda não se fazem presente nas unidades de ensino como deveriam. Assim sendo, ainda há uma lacuna no que é proposto nas universidades e o que é efetivado nas escolas. Por outro lado, questiona se o PPP está presente na escola por escolha da comunidade em constituir uma identidade para a instituição e definir os papéis dos atores envolvidos, ou é apenas por exigência da secretaria de ensino. Não se estaria atribuindo ao PPP, desde o início, uma visão apenas burocrática, regulatória e administrativa? Observem o argumento de Bussmann (2013, p. 37) acerca das razões do PPP. Diz a autora que "por razões pedagógicas e técnico-administrativas, inerentes ao compromisso da escola com a educação e o ensino, são reforçados hoje a necessidade e o desafio de cada escola construir seu próprio projeto político-pedagógico e administrá-lo".

Há questões para ser pensadas. O PPP não deve ser visto apenas por uma perspectiva pedagógica, no sentido de organização, nem por uma perspectiva técnicoadministrativa. Optar em olhar o PPP por esses dois vieses e exigir que cada unidade de ensino tenha esse documento é assumir que ele terá um fim em si mesmo. Não queremos negar as razões pedagógicas nem suas funções técnico-administrativas, mas olhá-lo por esse prisma é reduzi-lo demais. Talvez seja por esse ou por outro motivo que algumas escolas ainda não sabem como fazer e o que fazer com esse "documento". Na prática, o PPP não passa de um documento e, consequentemente, a comunidade escolar não atribuiu o seu verdadeiro sentido. Apesar da autora citada anteriormente sintetizar as razões que obrigam as escolas a construírem o PPP, ela ainda faz ressalvas importantes sobre o documento, conforme aponta:

Não se trata meramente de elaborar um documento, mas, fundamentalmente, de implantar um processo de ação-reflexão, ao mesmo tempo global e setorizado, que exige o esforço conjunto e a vontade política da comunidade escolar consciente da necessidade e da importância desse processo para a qualificação da escola, de sua prática, e consciente, também, de que seus resultados não são imediatos. (BUSSMANN, 2013, p. 37).

De modo geral, o PPP tem sido apontado como resolução para assegurar a qualidade do ensino e garantir a organização da escola. Esses apontamentos são essenciais, porém não tocam na questão de pensar a escola como comunidade. Isso é importante porque 
definir a escola como "comunidade escolar" não assegura que na escola exista uma comunidade constituída. Uma coisa é certa: a reunião de pessoas (atores sociais) em um espaço físico não garante a constituição de uma comunidade.

Para tanto, o PPP pode ser compreendido, no sentido stricto sensu, desde uma perspectiva técnico-burocrática a uma perspectiva dialógica de construção. Nota-se que, frequentemente, nas escolas, há um intuito de olhar apenas o caráter documental, burocrático e normatizador de regimento das agências de letramentos. Neste trabalho, compreendemos o PPP em seu sentido lato sensu. Em outros termos, olhar desta forma significa que o PPP pode ser visto como instância de constituição da escola como comunidade e, por sua vez, implica conceber que, nessa comunidade, os atores sociais (alunos, professores, gestores, funcionários e membros da comunidade em torno da escola) assumem papéis diferentes e, consequentemente, constituem identidades. Nesse sentido, abre-se o espaço para pensar na escola como comunidade e que os membros pertencem a ela de forma ativa, interativa e colaborativa. Isso porque argumentamos que as identidades são constituídas em práticas mediadas pela linguagem. Assim sendo, mesmo assumindo essas premissas, não significa negligenciar o aspecto formativo e o caráter regimental deste documental, tendo em vista que os sujeitos, as identidades se constituem em práticas discursivas e, que, por conseguinte, são eleitos valores, normas e atribuições. Importa afirmar que os valores, as normas e os significados não são dados a priori, eles são constituídos nas interações sociais. Isto é, a comunidade implica diferença e distinção entre diferentes papéis sociais e, consequentemente, diferentes atribuições. Assim, para a manutenção da escola como comunidade é essencial que cada membro assuma um papel, constitua uma identidade e desenvolva ações específicas.

Neste ponto, é importante afirmar que este trabalho se insere no campo da Linguística Aplicada nas interfaces com a educação, tendo em vista que almejamos lançar um olhar para as práticas enunciativas instituídas a partir do PPP. Nosso intento, não é o caráter organizador no sentido estrito, mas sim, lançar um olhar diferenciado para a escola como comunidade, para as práticas discursivas que são instituídas e, por conseguinte, para as diferentes posições que esses sujeitos ocupam. Nesse caso, acrescenta-se que assumimos uma concepção de comunidade e de educação conforme é defendida por Morin $(2009,2011)$. Morin (2009; 20011) e Hall (2011) contribuem para refinar uma concepção de identidade e de práticas identitárias. Recorre-se ainda a Alarcão (2001); a Gadotti (2000); Pimenta (1992), entre outros, para repensar a escola e suas práticas.

Pretendemos, neste trabalho, compreender a análise do projeto político pedagógico (PPP) como instrumento de reflexão da escola como comunidade. Para tanto, os 
objetivos específicos são: a) discutir o PPP (construção e efetivação) como instrumento que contribui para pensar a escola como comunidade; b) compreender o PPP como um instrumento de formação crítico-reflexiva de professores, gestores e profissionais da educação.

\section{A ESCOLA E A FUNÇÃO DO PROJETO POLÍTICO PEDAGÓGICO}

O PPP pode ser visto de várias formas. Uma delas pode ser expressa a partir da concepção de Padilha (2007, p. 25) que compreende esse gênero discursivo como "planejamento dialógico". O autor defende que esse planejamento: “[...] é, na verdade, uma forma de resistência e representa uma alternativa ao planejamento autoritário, burocrático, centralizado e descendente, que ganhou as estruturas dos nossos sistemas educacionais e das nossas redes escolares" (PADILHA, 2007, p, 25. Ênfase do autor).

Romão e Gadotti (1994, p. 42) expressam uma concepção de projeto político pedagógico a partir da perspectiva de construção de uma escola cidadã. Assim, defendem os autores,

[é] preciso entender o projeto-político-pedagógico da escola como um situar-se num horizonte de possibilidades na caminhada, no cotidiano, imprimindo uma direção que se deriva de respostas a um feixe de indagações tais como: que educação se quer e que tipo de cidadania se deseja, para que projeto de sociedade? A direção se fará ao entender e propor uma organização que se funda no entendimento compartilhado dos professores, dos alunos e demais interessados em educação (ROMÃO \& GADOTTI, 1994, p. 42. Ênfase nossa).

Nota-se que a preocupação central que os autores atribuem ao PPP é o caráter organizador, ou seja, o de sinalizar uma direção, um caminho e, portanto, propor uma direção. Colocar ênfase no caráter administrativo é importante para orientar a proposta pedagógica da escola, mas não é suficiente para compreender as especificidades do PPP e o papel que desempenha na comunidade escolar. Em uma perspectiva semelhante a dos autores mencionados, Passos (2013, p. 13-14) defende que

[o] projeto político-pedagógico, ao se constituir em processo democrático de decisões, preocupa-se em instaurar uma forma de organização do trabalho pedagógico que supere os conflitos, buscando eliminar as relações competitivas, corporativas e autoritárias, rompendo com a rotina do mando impessoal e racionalizado da burocracia que permeia as relações no interior da escola, diminuindo os efeitos fragmentários da divisão do trabalho que reforça as diferenças e hierarquiza os poderes de decisão.

Concordamos com as palavras de Passos (2013) no que concerne à construção democrática do PPP e a função deste documento em organizar as práticas de ensino. Porém, discordamos no que concerne à visão stricto sensu do PPP. Conforme assinalado 
anteriormente, entendemos a escola como comunidade e, como toda comunidade, é constituída por conflitos. Assim, os conflitos devem ser negociados, mas nunca deverão ser superados nem eliminados. A comunidade sempre será heterogênea e não será, em hipótese alguma, homogênea. O caráter democrático do PPP não é anular os conflitos e impor uma homogeneização. Esse caráter implica em eleger os conflitos como arena de discussão e celebrar a heterogeneidade. Por isso, defendemos o PPP como organizador do trabalho pedagógico, como espaço de construção de identidades e como forma de pensar a escola como comunidade.

Para Gadoti (1994, p. 579), o projeto

supõe rupturas com o presente e promessas para o futuro. Projetar significa tentar quebrar um estado confortável para arriscar-se, atravessar um período de instabilidade e buscar uma nova estabilidade em função da promessa que cada projeto contém de estado melhor do que o presente. Um projeto educativo pode ser tomado como promessa frente a determinadas rupturas. As promessas tornam visíveis os campos de ação possível, comprometendo seus autores e atores.

Note-se que para Gadoti (1994), o PPP e o planejamento da comunidade escolar devem estar alicerçados a partir dos conflitos e contradições. Em outros termos significa que a comunidade precisa sair de uma zona de conforto em busca de uma proposta que contemple os interesses dos membros dessa comunidade. Nesse caso, o PPP sempre será uma "ruptura com o presente e promessas para o futuro" (GADOTI, 1994, p. 579). Contudo, resta discutir que o futuro é o hoje e o agora, embora ele possa remeter a um futuro de longo prazo. Mas a escola deve ser vista no que foi no passado, no que ela é agora e pensar na escola que queremos construir no presente para o futuro.

Para Pimenta (1993, p. 70-80),

[o] projeto político-pedagógico resulta da construção coletiva dos atores da Educação escolar. Ele é a tradução que a Escola faz de suas finalidades, a partir das necessidades que lhe estão colocadas, com o pessoal - professores/alunos/equipe pedagógica/pais - e com os recursos de que dispõe. Esses elementos todos são mutáveis, modificam-se de ano para ano, no mesmo ano; de Escola para Escola, na mesma Escola. Por isso, o projeto não está pronto, mas em construção. Nele, a equipe vai depurando, explicitando, detalhando a inserção dessa Escola na transformação social. O projeto político-pedagógico ganha consistência e solidez à medida que vai captando sistematicamente a realidade na qual se insere. Daí ser a realização contínua de diagnósticos dessa realidade um instrumental importantíssimo nessa construção. Diagnóstico aberto, que não se cristaliza e que não se encerra na constatação da realidade, mas que lê e a Interpreta - o que supõe conhecimento/posicionamento teórico/prático da equipe. Esse trabalho com o diagnóstico os dados - serão definidor/redefinidor do conteúdo/forma do projeto político-pedagógico da Escola.(Ênfase da autora). 
Pimenta chama a atenção para o caráter coletivo do PPP, ou seja, ele resulta de um esforço mútuo. Ele não deve partir de apenas um membro da comunidade escolar e sim, deve ser resultado de uma colaboração entre os diferentes membros dessa comunidade. A autora traz ainda duas questões importantes. Primeiro, a característica inacabada do PPP, ou seja, ele não é um produto e, sim, um processo em construção. Segundo, o papel do diagnóstico que, por sua vez, não deve se "cristalizar" nem "encerrar" apenas em uma constatação. Esse diagnóstico -da escola- é importante para refletir e "interpretar" os diversos posicionamentos dos membros da comunidade escolar frente ao problema.

Complementando as afirmações acerca do PPP, Passos (2013, p. 15) assevera que

[p]ara que a construção do projeto político-pedagógico seja possível não é necessário convencer os professores, a equipe escolar e os funcionários a trabalhar mais, ou mobilizálos de forma espontânea, mas propiciar situações que lhes permitam aprender a pensar e a realizar o fazer pedagógico de forma coerente.

Observa-se que o argumento de Passos (2013) é importante, pois o PPP não significa que os membros que constituem a comunidade escolar deverão trabalhar mais e serem mais eficientes. O PPP não significa, em hipótese alguma, mais trabalho e eficiência. Uma comunidade não é constituída unicamente com os princípios de trabalho e eficiência, embora esses dois princípios sejam relevantes. Mais do que "permitir a aprender a pensar e a realizar o fazer pedagógico de forma coerente" (PASSOS, 2013, p. 15), o PPP deve ser visto como um gênero que em sua constituição e efetivação é propício pensar a escola como comunidade. O PPP não pode ser visto como "documento" que apenas define as atividades de cada membro da comunidade a ser realizada de forma isolada. Esse gênero possibilita pensar a escola como um todo e, por sua vez, sinaliza para uma concepção de comunidade.

A este ponto, poderíamos questionar: qual a relação do PPP com a comunidade escolar? A pergunta que exige uma resposta óbvia é por muitas vezes mal interpretada e, por conseguinte, mal compreendida. Desse modo, resulta uma flagelação e, com isso, uma fragmentação em compreender o PPP e a comunidade escolar. Existem pelo menos duas hipóteses para responder à pergunta. Hipótese i: a comunidade não existe $a$ priori, bem como os valores simbólicos, as regras da comunidade e as concepções. A comunidade resulta de um esforço mútuo em que todos participam ativa e colaborativamente. Em outras palavras, a comunidade surge da colaboração, da contradição, do conflito e da negociação. Assim sendo, a escola como comunidade surge de uma relação dialética e as negociações entre os diferentes pontos de vistas devem originar, em parte, a identidade da instituição. Portanto, a identidade 
da escola surge em meio a uma série heterogênea de concepções e valores e serão eleitos os que forem pertinentes para a instituição. De tal modo, a identidade da instituição é uma unidade no meio da diversidade. Isto porque os membros desta nova comunidade escolar fazem parte de outras comunidades, assumem outros papéis, desenvolvem outras ações. Hipótese ii: na construção dialógica do PPP os conflitos e as negociações fazem-se presentes. Em outros termos, é por meio da elaboração do gênero PPP que os diversos membros dessa comunidade se agrupam com diferentes concepções e valores para construir valores e significados em comum. Dessa forma, cada membro ocupa um lugar específico, uma função, desempenha um papel e atua de forma crítica sobre os outros papéis e demais funções. É em momentos de construção que cada membro atua, age e interage, e da mesma forma que ele afeta os outros pontos de vista, consequentemente, é afetado. Assim, há um posicionamento do sujeito, há a emergência da singularidade. Nesse ponto é importante acrescentar que os sujeitos possuem diferentes papéis nas sociedades e em diferentes comunidades, portanto, nessa atividade de construção do PPP, eles deixam emergir as identidades, porém, eles passam a constituir novas identidades e novos papéis frente à comunidade escolar. Isto pressupõe que a escola é uma comunidade singular em meio a heterogêneas comunidades adjacentes. $\mathrm{O}$ membro da comunidade escolar deve agir conforme os valores, significados e concepções instituídos na escola. Mesmo que sejam compatíveis com outras escolas, as comunidades não serão semelhantes. Isto porque os sujeitos são únicos, a comunidade é única. Assim sendo, os membros devem assegurar a unidade da comunidade em meio à diversidade (MORIN, 2011).

Comentamos anteriormente que a comunidade surge de uma relação dialética. Diferentes pontos de vistas, diferentes concepções, valores e significados entram em conflito para construir colaborativamente novos valores e concepções. Porém, é necessário destacar, é essencial ter cuidado no manejo com a relação dialética, porque o produto final, a síntese, deve revelar um esforço mútuo, porém não deve se constituir em uma acomodação e, com isso, permanecer em uma zona de conforto. Portanto, defendemos o seguinte: a escola deve constituir-se em comunidade e, por conseguinte, em uma arena em constantes conflitos. Pois é por meio do conflito que surgem novas identidades, novos valores, novos significados. Assim, a escola trabalha com a noção de identidades dinâmicas e híbridas. Desse modo, não há, portanto, espaço para identidades congeladas, cristalizadas e homogêneas.

Em síntese, argumentamos que é em volta da construção do gênero PPP que há indícios de construção da escola como comunidade. Pois, é a partir desse gênero que os membros se reúnem, discutem, expõem seus pontos de vistas, valores e concepções, e, a partir 
dessa heterogeneidade, há o surgimento de valores mútuos que irão caracterizar a identidade da escola e a emergência de identidades dos membros dessa comunidade. Nesse processo abrem-se espaços para discutir o pertencimento a um grupo em que há identificações, semelhanças e diferenças (HALL, 2011).

De acordo com Fontes (2002), é perceptível que, nas últimas décadas, cresce o interesse de pesquisadores em estudar as comunidades, porém, o autor ressalta ainda que o interesse vincula a compreender a comunidade não do ponto de vista como um lugar e sim, como um conjunto de relações sociais (FONTES, 2002, p. 19). Note-se, desse modo, que essa afirmação é compatível com a hipótese que assumimos de que a comunidade não é dada a priori, ela é constituída na relação entre os membros. Nesse sentido, é importante assinalar a afirmação de Fontes (2002, p. 19),

[e]sta abordagem tem sido decisiva para o entendimento dos laços, redes e relacionamentos entre trabalhadores e sua ação coletiva. Muitos destes estudos enfatizam a vida comunitária e as ligações dos trabalhadores com suas cidades, bairros e vizinhanças como fonte de assistência e ajuda mútua, solidariedade coletiva e cultura comum.

Em contrapartida, o conceito comunidade também apresenta imprecisão e divergência teórico-prática. Fontes pontua que os estudiosos na área discutem o significado e usam como argumento que comunidade sinaliza ora como "relações homogêneas" e ora como “ideia de harmonia e cooperação" entre os membros. Na verdade, não significa isso, comunidade pressupõe conflitos, acordos e cooperação. Assumir o conceito de comunidade é assumir que, em sua constituição, os conflitos entre os membros são constituintes, porém é necessário assegurar o respeito mútuo. Frisa-se que a comunidade deve respeitar e assegurar a ideia de que a "unidade humana não apague a diversidade, e que a da sua diversidade não apague a da unidade", conforme afirma Morin (2011, p. 49-50). É no respeito a traços singulares e comuns que se constitui uma comunidade. Uma comunidade pauta no desenvolvimento humano, desenvolvimento da comunidade escolar, desenvolvimento da formação cidadã. Assim, afirma Morin (2011, p. 49), "todo desenvolvimento verdadeiramente humano significa o desenvolvimento conjunto das autonomias individuais, das participações comunitárias e do sentimento de pertencer à espécie humana”.

A perspectiva de assumir a escola como comunidade pressupõe de início assumir a noção de complexidade tal qual formulada por Edgard Morin. Para esse autor,

[c]omplexus significa o que foi tecido junto; de fato, há complexidade quando elementos diferentes são inseparáveis constitutivos do todo (como o econômico, o político, o sociológico, o psicológico, o afetivo, o mitológico), e há um tecido interdependente, interativo e inter-retroativo entre o objeto de conhecimento e seu contexto, as partes e o 
todo, o todo e as partes, a partes entre si. Por isso, a complexidade é a união entre a unidade e a multiplicidade (MORIN, 2011, p. 36).

A noção de complexidade, a partir de Morin, é essencial para se refletir a escola como comunidade, uma comunidade complexa que mantém relação com outras comunidades. A comunidade escolar não é, pelo menos não deveria ser na prática, isolada, fragmentada, descontextualizada. Pensar a escola como comunidade é pensar numa comunidade aberta ao diálogo, aberta ao novo, aberta às incertezas e que tenha a consciência e o sentimento de pertencimento e que está na relação mútua com o outro.

Falar em comunidade, em sentimento de pertencimento e de relação mútua com o outro, é necessário refletir, a partir de Morin, de que é necessário “aprender a 'estar aqui' no planeta". Assim, portanto, devemos primeiramente refletir nos sentidos e significados de estarmos aqui em comunidade. O que significa 'estar aqui'? Morin $(2011$, p. 66) responde:

\footnotetext{
Aprender a estar aqui significa: aprender a viver, a dividir, a comunicar, a comungar; é o que se aprende somente nas culturas singulares - e por meio delas. Precisamos doravante aprender a ser, a viver, a dividir e a comunicar como humanos do planeta Terra, não mais somente pertencer a uma cultura, mas também sermos terrenos. Devemos dedicar-nos não só a dominar, mas a condicionar, a melhorar, a compreender. (Ênfase nossa).
}

Estar aqui não significa apenas e unicamente uma presença física, mas sim, como diz o autor, "aprender a viver, a dividir, a comunicar, a comungar". O autor defende que no humano devem ser inscritas quatro consciências de diferentes especificidades, mas que unidas permitem pensar o humano no mundo e como ser do mundo. São elas: a consciência antropológica, a consciência ecológica, a consciência cívica terrena, a consciência espiritual da condição humana.

Note-se que é a partir do exercício de pensar a escola, do planejar o fazer na escola que se institui um processo de reflexão sobre a escola como comunidade e o papel social que cada ator social deverá assumir. E, nesse caso, o PPP assume uma dimensão essencial. Percebe-se, desse modo, o nosso intento de assegurar que o PPP não é mais um documento burocrático e sim, um artefato que incide diretamente na construção de uma escola como comunidade. Nesse sentido, destacamos o argumento de Alarcão (2001, p. 76), para quem,

[o] projeto político-pedagógico-curricular, como expressão concreta do trabalho coletivo na escola, por um lado, é um elemento mediador entre a cultura interna à escola e a cultura externa do sistema de ensino e da sociedade, na conquista da autonomia da organização escolar e, por outro, poderá tornar-se instrumento viabilizador da construção da escola reflexiva e emancipadora. 
Urge, nesse contexto, repensar a escola, repensar a comunidade e repensar o nosso papel de professor-mediador. Importa mencionar aqui que não é nada fácil para a escola assumir a proposta discutida neste trabalho, porém é extremamente necessário, pois a unidade escolar contemporânea reivindica novas estratégias, novas ações, novos papéis, múltiplas funções. A sociedade precisa analisar a escola que temos, a escola que queremos e o que estamos fazendo para a reconstrução de novos paradigmas em educação. A este ponto destacamos o argumento de Alarcão (2001, p. 76). Assim, assevera a autora,

[d]iante dessa exigência, a ação de projetar e executar implica sair de um estado confortável instituído e consolidado, romper com a rotina e correr o risco de enfrentar um período de instabilidade, denominado aqui constituinte (em construção) e lançar-se em busca de uma possível nova estabilidade mais qualificada.

É no enfrentamento do novo, das incertezas, que surgirá a escola que a sociedade exige. Discutir as concepções e conceitos de membros da comunidade escolar é de suma importância. Discutir paradigmas em educação é essencial para se refletir acerca do posicionamento dos membros da comunidade escolar diante da realidade educacional. Um paradigma tanto pode elucidar questões quanto pode ofuscar. Conforme diz Morin (2011, p. 26), "um paradigma pode, ao mesmo tempo, elucidar e cegar, revelar e ocultar. É no seu seio que se esconde o problema-chave do jogo da verdade e do erro".

\section{SOCIEDADE, ESCOLA E IDENTIDADE.}

A questão que parece ser simples acaba ganhando uma dimensão complexa. Isto é, a escola que deveria valorizar as culturas e os valores simbólicos que os diversos membros da comunidade escolar constituíram, na maioria das vezes, negligencia em prol de desenvolver um currículo que não reflete os interesses e perspectivas de alunos nem dos professores. Conforme Liberali (2009, p. 11-12), “[...] no contexto de vida atual, a proposta que se coloca é pensar a 'vida que se vive' (Marx e Engels, 2006, p. 26) e em formas de transformá-la para uma melhor participação e coexistência”. A autora pontua ainda que nas práticas de ensino-aprendizagem, "o foco recai sobre formas de ensinar pautadas por uma reflexão sobre a vida”. Isto pressupõe que o programa político pedagógico da escola deve ter como foco celebrar a vida na escola e, por conseguinte, instituir práticas de ensino significativas que contribuam para a formação de alunos cidadãos, críticos, reflexivos e conscientes de seu papel social. Sobre essa questão, Teixeira (1994, p. 63-64) defendia de 
forma contundente a proposta de constituir um programa de ensino pautado na cultura da comunidade escolar. Assim, diz o autor,

[o] programa escolar será a própria vida da comunidade, com o seu trabalho, as suas tradições, as suas características, devidamente selecionadas e harmonizadas. [...] A regionalização da escola que, entre nós, terá de caracteriza-se pela municipalização da escola, com a administração local, programa local e professor local, embora formado pelo Estado, concorrerá em muito dissipar os aspectos abstratos e irreais da escola imposta pelo centro, com programas determinados por autoridades remotas e distantes, e servida por professores impacientes e estranhos ao meio, sonhando perpetuamente com redentoras remoções (TEIXEIRA, 1994, p. 63-64. Ênfase nossa).

O autor defende a emancipação da escola, pois ele visava à criação de uma escola autônoma, democrática e regional. Quando o autor fala em uma escola regional e local é com o intuito de resgatar o contexto histórico, social e político dos sujeitos que constituem a comunidade escolar. Uma escola que celebre a "vida como ela é", e, não, em hipótese alguma, uma "realidade" projetada em modelos universais. Portanto, abre espaço para admitir e valorizar a cultura local. Assim, a escola deve partir do que os alunos já construíram com base nas suas interações sociais em um determinado contexto social específico.

Teixeira (1994) fala de administração, de programa e professores locais, com o intuito de resgatar a historicidade dos sujeitos envolvidos. Uma administração local centrada na realidade da escola, pois cada escola tem suas especificidades. Assim, urge uma administração e um programa específico. Não precisamos desenvolver uma argumentação longa para sustentar que a escola precisa de uma gestão, um planejamento e uma proposta que respondam às necessidades específicas e singulares. A escola assume a difícil tarefa de celebrar aspectos universais, globais, regionais e locais. Conforme Morin (2011), uma educação do futuro deve articular o conhecimento com as culturas, pois o conhecimento é histórico e cultural.

A defesa de uma escola local (Teixeira, 1994), ou seja, com princípios e valores locais, abre uma outra questão, a questão da identidade. Assim, como pensar em uma identidade local levando em consideração os efeitos da globalização e da interculturalidade? Na contemporaneidade, Hall $(2011$, p. 07) menciona que "as velhas identidades, que por tanto tempo estabilizaram o mundo social, estão em declínio, fazendo surgir novas identidades e fragmentando o indivíduo moderno, até aqui visto como sujeito unificado". O argumento de Hall é importante para refletir a escola, os sujeitos e a questão da identidade local e global. Por mais que se dê ênfase a questões locais, é preciso mencionar que o local, hoje, não está isolado do resto mundo, da mesma forma que ele age e interage com as outras partes. Hall (2011, p. 07) menciona que 
"a crise de identidade" é vista como parte de um processo mais amplo de mudança, que está deslocando as estruturas e processos centrais das sociedades modernas e abalando os quadros de referência que davam aos indivíduos uma ancoragem estável no mundo social.

Desse modo, podemos afirmar que o papel da escola em celebrar aspectos da cultura local significa o compromisso com a preservação de hábitos e de costumes que foram instituídos, mas, por outro lado, não pode negar o caráter móvel das identidades e dos efeitos da crise de identidade. Para a escola é difícil ter que tocar em questões que não são mais referências mestras que determinam o comportamento das pessoas e os papéis que elas desempenham. Esse fator é importante porque a escola e o professor devem ser questionados a rever seus papéis e posturas frente às novas exigências das culturas. Entre o local e o global em direção ao pós-moderno, Hall (2011, p. 73) argumenta que

[a]lguns teóricos argumentam que o efeito geral desses processos globais tem sido o de enfraquecer ou solapar formas nacionais de identidade cultural. Eles argumentam que existem evidências de um afrouxamento de fortes identificações com a cultura nacional, e um reforçamento de outros laços e lealdades culturais, "acima" e "abaixo" do nível do estado-nação. As identidades nacionais permanecem fortes, especialmente com respeito a coisas como direitos legais e de cidadania, mas as identidades locais, regionais e comunitárias têm se tornado mais importantes. Colocadas acima do nível da cultura nacional, as identificações "globais" começam a deslocar e, algumas vezes, a apagar, as identidades nacionais.

Em outro excerto, Hall (2011, p. 74) assevera que

[a]lguns teóricos culturais argumentam que a tendência em direção a uma maior interdependência global está levando ao colapso de todas as identidades culturais fortes e está produzindo aquela fragmentação de códigos culturais, aquela multiplicidade de estilos, aquela ênfase no efêmero, no flutuante, no impermanente e na diferença e no pluralismo cultural descrita por Kenneth Thopson (1992), mas agora numa escala global - o que poderíamos chamar de pós-modeno global.

Nota-se, a partir dos argumentos de Hall, que não há mais espaço para pensar em identidades e em referências simbólicas estáveis e homogêneas, pois estamos diante de identidades e referências híbridas e dinâmicas e, por conseguinte, heterogêneas. Portanto, as mudanças sócio-histórico-culturais sinalizam para uma reflexão acerca de "identidades partilhadas" (HALL, 2011, p. 74). Nesse ponto, é importante destacar que Morin (2011, p. 66) discute a importância de uma compreensão mais apurada acerca da identidade. Mais do que isso, o autor coloca em discussão a problemática da identidade e a consciência terrena. Diante dessa problemática, aponta questões importantes para repensar o papel da escola. Assim, afirma o autor,

[a] união planetária é a exigência nacional mínima de um mundo encolhido e interdependente. Tal união pede uma consciência e um sentimento de pertencimento mútuo 
que nos una à nossa Terra, considerada como primeira e última pátria. Se a noção de pátria comporta identidade comum, relação de filiação afetiva à substância tanto materna como paterna [...], enfim, uma comunidade de destino, então podemos avançar a noção de Terrapátria. [...] temos todos uma identidade genética, cerebral, afetiva comum em nossas diversidades individuais, culturais e sociais. Somos produto do desenvolvimento da vida, da qual a Terra foi matriz e nutriz. Enfim, todos os humanos, desde o século XX, vivem os mesmos problemas fundamentais de vida e de morte e estão unidos na mesma comunidade de destino planetário (MORIN, 2011, p. 66).

A partir das pontuações de Morin (2011), é possível pensar: será que a escola em suas práticas incita a questão do pertencimento, ou seja, será que os alunos são convidados a refletir sobre os laços de pertencimentos mútuos? Por outro lado, uma questão se apresenta. Os professores e os profissionais da educação refletem acerca da questão do pertencimento? $\mathrm{Na}$ prática, o professor possui sentimento de pertencimento à comunidade escolar? $\mathrm{O}$ autor discute questões relacionadas ao pertencimento "terreno", ou seja, somos e estamos no mundo, herdamos e transmitimos valores.

No excerto anterior é possível identificar a tentativa que Morin (2011) faz de assegurar que na singularidade, na individualidade, existe uma "identidade em comum". Em outras palavras, o autor quer enfatizar que existe a unidade na diversidade, que formamos comunidade a partir do reconhecimento de traços que são comuns a todos. Porém, Morin (2011) não anula a singularidade de cada um. Isto é, uma unidade na diversidade, sinalizando que a identidade se constitui a partir do outro. Nesse caso estão incluídas as relações sociais, as relações com o mundo, e também as características genéticas e cerebrais, embora estas últimas não sejam determinantes. Diante dos argumentos de Morin (2011, p. 66), são apontadas questões para se refletir a escola como comunidade e, por sua vez, destaca-se o papel da escola na formação humana.

A partir das questões que estão postas neste trabalho, questionamos: como a escola deve organizar o currículo e as propostas escolares? Morin (2011, p. 73) responde a essa pergunta afirmando que "o papel da educação do futuro" é propor ao ser humano "enfrentar as incertezas ligadas ao conhecimento". Mas o que significa "enfrentar as incertezas" e qual o significado que a afirmação do autor desempenha na educação? Enfrentar as incertezas significa que somos convidados a refletir acerca do conhecimento construído, das relações sociais e das relações com a sociedade, bem como somos incitados a uma autorreflexão. É no confronto com a incerteza, e em busca de certeza(s), que poderá emergir um processo crítico-reflexivo. Qual o papel de enfrentar as incertezas na educação? Assumir o princípio das incertezas redireciona o papel da escola e do professor. Em outros termos, a escola não assume mais o compromisso de transmitir conhecimentos e sim, ela constitui um 
espaço de construção. Uma construção que parte do enfrentamento das incertezas de sujeitos sociais (alunos e professores) que questionam, interrogam e se posicionam de forma crítica. Assim, deixa-se de reproduzir uma "educação bancária" (FREIRE, 1996) e constitui uma educação pautada com o compromisso social, do respeito mútuo, em que os sujeitos sociais agem e interagem. O papel do professor também muda, pois ele também é convidado a se deparar com as suas incertezas. Nesse contexto, acredita-se que o PPP (elaboração e efetivação) deve ser pautado para enfrentar as incertezas. Incertezas do professor sobre si mesmo, sobre o conhecimento, sobre a sua relação com a sociedade. Asseguramos, portanto, uma concepção de conhecimento que não é pronto e construído e, sim, uma concepção de conhecimento que é constituído por meio da colaboração de atores sociais.

\section{RELATO DE EXPERIÊNCIA COM FORMAÇÃO DE PROFESSORES: Desmistificando estereótipos e abalando discursos cristalizados}

Conforme mencionado anteriormente, este trabalho é resultado de uma proposta de formação de professores. Essa proposta foi desenvolvida em dois grupos distintos, um grupo formado por professores e coordenadores que estão inseridos em práticas de ensino, e outro destinado à formação inicial de professores, desenvolvido com alunos do curso de Letras e Pedagogia. Assim sendo, a atividade se insere como plano de trabalho de um projeto de pesquisa e extensão intitulado "Práticas pedagógicas inclusivas: a inclusão de professores em debate", cadastrado no Comitê de Ética da Universidade Estadual do Ceará. Esse projeto tinha como propósito lançar um olhar mais atento acerca do papel do professor nas práticas de ensino. Porém, com o desenvolvimento das atividades, ficou nítida a importância de se desenvolver atividades de formação que contemplem as práticas escolares, as discussões acerca do currículo e o planejamento pedagógico em uma perspectiva que compreenda a escola como comunidade. Neste trabalho serão discutidas apenas as atividades do curso de formação continuada de professores.

Para tanto, a proposta de formação foi desenvolvida em três momentos distintos. O primeiro correspondia a uma discussão acerca de conceituar e discernir a funcionalidade do PPP nas unidades de ensino. O segundo momento foi destinado à produção de textos reflexivos acerca dos conceitos de escola, comunidade, conhecimentos, saber, aprendizagem, aluno e professor. Por último, o terceiro momento foi destinado à leitura, discussão e análise do PPP das escolas, finalizando com a apresentação e discussão das análises. Por mais que a proposta fosse dividida em três momentos distintos, eles não foram excludentes, e sim, 
complementares. A divisão foi uma escolha apenas didática como forma de trabalhar teoria e prática. Passaremos a descrever e analisar os momentos de formação.

O primeiro momento foi desenvolvido a partir de discussão acerca do PPP. As discussões foram realizadas em grupos, propiciando a exposição de conceitos e preconceitos acerca da questão discutida. Após essa discussão foram feitas leituras de textos sobre o PPP, comunidade, identidade e formação cidadã. Finalizada a leitura, os grupos foram incitados a discutir os textos estudados e a comparar com a discussão inicial. Nesse momento, houve confronto entre o que havia sido discutido no início e o que fora problematizado a partir das leituras. Havia pontos importantes. Por um lado, professores e coordenadores que tinham uma visão mais ampla da escola e do PPP, porém lamentavam que não podiam fazer nada na escola - que sozinhos não podiam mudar a realidade -. Por outro, havia professores que não tinham uma leitura mais aprofundada sobre o tema. Ambos os grupos viam apenas o caráter formal, burocrático do PPP, bem como destacavam as dificuldades em compreender a escola como uma comunidade que é constituída coletivamente. Nesse ponto, a discussão acerca do conceito de comunidade foi importante para desmistificar a visão de que a comunidade é constituída a priori e, que apenas a junção de um grupo de atores sociais não forma uma comunidade. Acrescenta-se ainda que alguns professores apresentavam dificuldades e resistência em compreender o PPP como uma proposta de formação e transformação da unidade escolar e, que, por sua vez, possui sentidos importantes na construção da identidade da instituição.

A resistência dos professores em relação à formação e em compreender o PPP em uma perspectiva mais ampla pode ser analisada de múltiplas formas. Primeiro diz respeito à forma como o PPP tem sido concebido teoricamente por alguns autores, bem como à forma como é abordado na formação inicial e contínua de professores. Em outras palavras: o PPP é um documento que é exigido porque deve conter informações acerca da unidade de ensino, pois caso ela seja "questionada", o documento deve ser apresentado a Secretaria de Educação. Nota-se que o PPP, em algumas escolas, cumpre a função de ser escrito apenas para a Secretaria de Educação. Dessa forma, ele não passa de um “documento". Essa é uma visão reducionista do PPP e da escola. A resistência dos professores, por outro lado, sinaliza que muitas formações propostas não atendem às necessidades da escola nem dos próprios professores. São formações que não contribuem para melhorar a prática pedagógica, e eles têm dificuldades de modificar as práticas instituídas e ressignificá-las.

As mudanças nas práticas de ensino devem partir dos profissionais da educação. A proposta de formação não é oferecer métodos de ensino nem muito menos propostas e 
abordagens e, sim, propiciar condições para que os profissionais da escola reflitam sobre o seu fazer e, sobretudo, acerca dos efeitos e impactos das práticas instituídas.

No caso da formação que desenvolvemos, em hipótese alguma tínhamos o intento de oferecer um arcabouço conceitual e metodológico de como escrever um PPP. O nosso objetivo era fazer com que o professor e o coordenador pedagógico refletissem sobre a escola como comunidade, bem como sobre a importância e a funcionalidade deste gênero.

A questão da rejeição foi tema de debate no grupo. Primeiro, porque alguns professores veem os cursos com uma ideia formada de que será apenas repetição do que eles já sabem. Assim, discutimos sobre o processo de construção do conhecimento e a importância do professor assumir o papel de professor-estudante-pesquisador. Foi discutida a importância de se enfrentar as incertezas do conhecimento e não se colocar numa posição de que tudo já foi aprendido. Não há um professor formado que não precise saber de mais nada. Essa postura dificulta aos profissionais refletir sobre suas práticas e assim, virem a ressignificá-las. Segundo, foi importante porque na escola, durante a produção do PPP, devem ser discutidos os temas que a escola deve abordar nas formações, ou seja, desenvolver formações de acordo com as necessidades da comunidade e não a partir de uma imposição. Os professores reclamam, mas não se colocam numa posição crítica que signifique reivindicar seus direitos de ter uma formação que contemple os seus anseios.

O segundo momento, que consistiu na produção de textos reflexivos acerca dos conceitos de escola, comunidade, conhecimentos, saber, aprendizagem, aluno e professor, foi desenvolvido por duas razões: a) com o propósito de instituir, a partir da escrita de textos, uma prática reflexiva que possibilitasse aos formandos confrontar as discussões do grupo com a prática que é desenvolvida na escola; b) como estratégia de construir um portfólio que registrasse as atividades que foram desenvolvidas para que, no final, os participantes pudessem analisar suas produções e, por conseguinte, servisse de reflexão acerca do que foi abordado. A produção e a análise dos textos são importantes porque propiciam a reflexão e, por conseguinte, deslocamentos de pontos de vistas, de concepções.

O terceiro momento da formação que, por sua vez, contemplou a leitura, discussão e análise do PPP, finalizou com a apresentação e discussão das análises. Nesse momento pudemos ver de forma nítida como o PPP permanece à margem na escola.

Constata-se que, na prática, há escolas com projetos bem elaborados que não são postos em práticas e, por outro lado, há projetos que carecem de uma melhor elaboração, porém a instituição desenvolve várias atividades que não estão planejadas no PPP. Em outras palavras, o PPP não representa a escola e, por conseguinte, não assume uma função social. As 
propostas bem elaboradas que apresentavam ações importantes para a escola não eram desenvolvidas. O motivo apontado era a falta de definição de papéis, ou seja, havia uma proposta a ser desenvolvida, mas os atores que iam colocá-la em prática não haviam sido designados. Esse foi um dado importante para ser discutido no grupo. A partir desse dado, voltamos à discussão sobre o conceito de comunidade e o papel que cada membro desenvolve. Discutimos também que o papel do professor não é apenas com as aulas que são ministradas, ele pode assumir, na medida do possível, outras funções, inclusive a de compreender como as atividades estão sendo desenvolvidas. Nesse ponto, o grupo fícou bastante dividido, de um lado os coordenadores apontando o excesso de atividades, do outro, os professores resistentes à importância de participar de atividades da instituição e não apenas das aulas que são ministradas. Segundo os coordenadores, muitos professores mostram resistência em desenvolver um trabalho de forma colaborativa com a gestão. Por outro lado, os professores alegam não ter tempo nem abertura na instituição.

A partir do confronto de opiniões, vimos o quanto, em algumas escolas, há fragmentação. Cada membro desenvolve atividades isoladas. Assim, o grupo foi questionado: que comunidade é esta? Em geral, os professores apontaram que a "culpa" era do "sistema". Nesse ponto, eles foram questionados: o que é o sistema, quem compõe o sistema, os professores não fazem parte do sistema? A atitude do professor de se isentar do processo foi discutida. O que isso revela? Por um lado, discutimos o fato de que docentes atribuírem culpa ao sistema corresponde a uma forma de se isentar - no sentido de autoproteção - e uma forma de não se responsabilizar pelos problemas da comunidade escolar. Assim, voltamos à discussão sobre o conceito de comunidade e definição de papéis sociais na comunidade escolar. Não é para responsabilizar o professor pelos problemas da escola, mas os problemas da escola devem ser discutidos na comunidade escolar da qual os professores fazem parte. $\mathrm{Na}$ comunidade cada membro assume papéis e funções. Da mesma forma que no sistema. $\mathrm{O}$ sistema de ensino é formado por quem atua direta ou indiretamente na educação, especialmente por professores. A atitude de alguns professores de se isentar e culpar o sistema representa um sentimento de não pertencimento ao sistema e, consequentemente, a comunidade escolar?

Nota-se ainda, a partir das discussões, uma imprecisão teórica e conceitual em definir ensino-aprendizagem, educação, bem como não ficam claras as definições de aluno, coordenador e professor, nem os papéis que cada um assume na escola. Observe-se que no estudo do PPP foi possível identificar pontos essenciais para serem refletidos na escola e/ou 
em cursos de formação (inicial e/ou contínua) de docentes. O curso de formação foi se constituindo a partir das características dos participantes e dos anseios que eles apresentavam.

\section{CONSIDERAÇÕES FINAIS}

O objetivo geral deste trabalho consistiu em compreender a análise do projeto político pedagógico (PPP) como instrumento de reflexão da escola como comunidade. Assim, constatamos que os conceitos de PPP, de comunidade e de escola são dissociáveis na prática que investigamos. Pensar a escola como comunidade e lançar um olhar diferenciado para o PPP constituem questões importantes para refletir na/com a escola. As afirmações de que o PPP é visto apenas pelo víeis stricto sensu foi concretizada na teoria e na prática. Alguns teóricos que se propõem a estudá-lo atribuem seu caráter democrático, porém normatizador, documental e diretivo; os participantes dos cursos de formação o veem da mesma forma. A diferença entre a teoria e a prática é que os teóricos dão ênfase ao PPP e mostram sua função, mesmo que seja a de organização. Muitos participantes dos grupos de formação não viam nem essa possibilidade.

Desse modo, o nosso intento de ver o PPP a partir de uma perspectiva lato senso foi importante porque, pelo menos, tentamos lançar um olhar diferente e enxergar a sua importância na constituição da escola como comunidade. Essa questão levantou a hipótese de que a comunidade não é dada a priori, ela é constituída colaborativamente. Foi importante, também, para tocar questões adormecidas e conceitos e preconceitos cristalizados (BEZERRA, 2011).

Apesar de finalizar este trabalho, enfatizamos a necessidade de outras possibilidades de reflexões para compreender a escola como comunidade e a importância do PPP na comunidade escolar. Para tanto, destacamos a importância da implicação da Linguística Aplicada enquanto área transdisciplinar que oferece um corpo teóricometodológico para repensar a escola como comunidade. Assim, urge a necessidade em repensar a Linguística Aplicada como campo que requer, por sua vez, problematizar questões mais amplas do que apenas as práticas de ensino-aprendizagem de línguas. Desse modo, delineia-se a importância do linguista aplicado em compreender a escola e suas múltiplas formas de organização e funcionamento. 


\section{REFERÊNCIAS}

ALARCÃO, I. Escola reflexiva e a nova racionalidade. Porto alegre: ArtMed, 2011.

BEZERRA, L. C. S. Função docente: pontuações acerca da formação de professores de línguas. VII Seminário Nacional sobre o ensino de línguas materna e estrangeira e de literatura. Campina Grande, PB: Editora da UFCG, 2011.

BUSSMANN, A. C. O projeto político-pedagógico e a gestão escolar. IN: PASSOS, I. A. V.(ORG.) Projeto político-pedagógico da escola: uma construção possível. Campinas: SP: Papirus, 2013.

FREIRE, P. Pedagogia da autonomia. Saberes necessários à prática educativa. São Paulo: Paz e Terra, 1996.

FONTES, P. R. R. Comunidade operária, migração nordestina e lutas sociais: São Miguel Paulista (1945-1966). Tese (Doutorado) - Universidade Estadual de Campinas, Instituto de Filosofia e Ciências Humanas. 2002.

GADOTI, M. Perspectivas atuais da educação. São Paulo em Perspectiva, 14 (2), 2000.

Educação para Todos. Brasília: MEC, 1994.

Pressupostos do projeto pedagógico. Anais da Conferência nacional da . Perspectivas atuais da educação. (ORG.). Porto Alegre: ArtMed, 2000.

HALL, S. A identidade Cultural na pós-modernidade. Rio de Janeiro, RJ: DP\&A, 2011.

LIBERALI, F. C. Atividade Social nas aulas de língua estrangeira. São Paulo: Moderna, 2009.

MORIN , E. Os sete saberes necessários à educação do futuro. São Paulo: Cortez; Brasília, DF: UNESCO, 2011.

A cabeça bem feita: repensar a reforma, reformar o pensamento. Rio de Janeiro, RJ: Bertrand Brasil, 2012.

PIMENTA, Selma Garrido. Questões sobre a organização do trabalho na escola. Série Idéias: a autonomia e a qualidade do ensino na escola pública. no 16, São Paulo: 1993. http://www.crmariocovas.sp.gov.br/prp_a.php?t=005

. O pedagogo na escola pública. 2. ed. São Paulo: Loyola, 1991.

PADILHA, P. R. Planejamento dialógico: como construir o projeto político pedagógico da escola. São Paulo: Cortez, 2007. 
PASSOS, I. A. V. Perspectivas para a reflexão em torno do projeto político-pedagógico. IN: PASSOS, I. A. V.; RESENDE, L. M. G. (Orgs.) Escola: espaço do projeto políticopedagógico. Campinas: SP: Papirus, 1998.

. Projeto político-pedagógico da escola: uma construção coletiva. IN: PASSOS, I. A. V.(ORG.) Projeto político-pedagógico da escola: uma construção possível. Campinas: SP: Papirus, 2013.

TEIXEIRA, A. Educação não é privilégio. RJ: 1994.

ROMÃO \& GADOTTI, M. Projeto da escola cidadã: a hora da sociedade, IPF, 1994.

\section{O AUTOR}

Luiz Carlos Souza Bezerra é doutorando em Linguística Aplicada e Estudos da Linguagem pela Pontifícia Universidade Católica de São Paulo (LAEL/PUC-SP). Atua com formação de professores nas áreas de linguagem e educação; educação especial/inclusiva; currículo e planejamento pedagógico.

E-mail: bezerralcs@gmail.com 